\title{
Infusion rate and pharmacokinetics of intravenous pamidronate in the treatment of tumour-induced
} hypercalcaemia

\author{
D.J. Dodwell ${ }^{1}$, A. Howell ${ }^{1}$, A.R. Morton ${ }^{2}$, P.T. Daley-Yates ${ }^{3}$ \\ and C.R. Hoggarth ${ }^{3}$
}

${ }^{1}$ Department of Medical Oncology, Christie Hospital, Wilmslow Road, Manchester M20 9BX, ${ }^{3}$ Department of Pharmacy, University of Manchester, Manchester M13 9PL, UK, and ${ }^{2}$ Department of Medicine, Queen's University, Kingston, Ontario, Canada

\begin{abstract}
Summary: We report the results of two consecutive randomized studies in the treatment of malignant hypercalcaemia with intravenous pamidronate. Overall normocalcaemia was achieved in greater than $90 \%$ of patients and a single infusion of $60 \mathrm{mg}$ pamidronate given over 2 hours was as effective in restoring normocalcaemia as infusions given over 4,8 or 24 hours. Similarly duration of normocalcaemia after treatment with pamidronate and the control of the symptoms of hypercalcaemia were independent of infusion rate. Study of the pharmacokinetics of pamidronate in the treatment of hypercalcaemia show this drug to have a very high clearance due to calcified tissue retention and renal excretion. The initial half life of the drug in plasma is very short and most of the drug is cleared before distribution equilibrium is achieved. Short infusions of pamidronate are as safe and effective as infusions given over a longer time and are therefore to be preferred because of their greater convenience.
\end{abstract}

\section{Introduction}

Bisphosphonates, structural analogues of pyrophosphate, are rapidly becoming established as the treatment of choice for the hypercalcaemia of malignancy. ${ }^{1-3}$ These agents with powerful inhibitory effects on osteoclast function are also of interest as potential agents for the control of lytic bone disease. ${ }^{4,5}$ Pamidronate like other bisphosphonates is poorly absorbed ${ }^{6,7}$ and the gastrointestinal toxicity of pamidronate given by the oral route coupled with the nausea and vomiting of malignant hypercalcaemia, has meant that interest has focused on intravenous pamidronate for the treatment of this condition. Of currently available compounds pamidronate (Aredia, Ciba Geigy) appears the most effective in restoring normocalcaemia. $^{8}$ The ideal dose for maximum response remains unclear but appears to be of the order of $60-90 \mathrm{mg}$.

It has recently been demonstrated that a single infusion of pamidronate is as effective as repeated infusions (to give the same total dose) and is therefore to be preferred because of its simplicity. ${ }^{10-12}$ However, the optimum rate of infusion is not known. Early reports of renal failure due to

Correspondence: D.J. Dodwell, B.Sc., M.R.C.P., Cookridge Hospital, Leeds, UK.

Accepted: 10 January 1992 rapid infusion of etidronate and clodronate ${ }^{13}$ have led to the use of infusion rates of $15 \mathrm{mg}$ per hour or less. It was also believed that a slower infusion rate would facilitate greater uptake of pamidronate into bone and produce a more prolonged therapeutic effect. ${ }^{12}$ Also, because until recently there was no reliable assay for pamidronate in serum or urine, it has not been possible to study the pharmacokinetics of pamidronate, or any other bisphosphonate, in relation to therapeutic effect.

In order to determine whether the infusion rate of pamidronate affects the control of hypercalcaemia we have compared the use of $60 \mathrm{mg}$ of pamidronate administered over 2, 4, 8 and 24 hours for the treatment of malignant hypercalcaemia in two randomized trials. In addition we have studied the pharmacokinetics of intravenous pamidronate in seven patients receiving an 8 or a 24 hour infusion of $60 \mathrm{mg}$ pamidronate.

\section{Patients and methods}

Fifty patients who presented with clinically established malignant disease and a serum calcium concentration (corrected for serum albumin) greater than $2.9 \mathrm{mmol} / 1$ were entered into two consecutive prospective randomized clinical studies. 
All patients were entered after adequate saline rehydration. No concurrent antitumour therapy was given until normocalcaemia had been achieved. Retreatment with pamidronate was given when serum calcium exceeded $2.65 \mathrm{mmol} / \mathrm{l}$ and thereafter at appropriate intervals for individual patients.

Patients' clinical state and symptoms were recorded daily by patients and nursing staff by the use of a simple scoring system. Symptoms related to hypercalcaemia (nausea and vomiting, anorexia, pruritus, weakness, central nervous system symptoms, thirst, constipation and bone pain) were assessed as absent, mild, moderate or severe and scored correspondingly from 0 to 3 .

Statistical analyses of static parameters between the groups were performed by the use of the Wilcoxon two-sample rank sum test. ${ }^{14}$ Differences between dynamic variables were tested by using Friedman's non-parametric two way analysis of variance. As non-parametric statistics were used graphs display median values and no error bars.

\section{Study 1}

The first study compared $60 \mathrm{mg}$ of pamidronate given by intravenous infusion in $500 \mathrm{ml}$ of normal saline over 2 hours (nine patients) or over 4 hours (11 patients).

\section{Study 2}

The second study compared $60 \mathrm{mg}$ pamidronate given by intravenous infusion in $500 \mathrm{ml}$ normal saline over 8 hours (15 patients) or 24 hours (15 patients).

Biochemical analyses of serum sodium, potassium, creatinine, urea, calcium, albumin and phosphate were performed daily for the first week and thereafter at weekly intervals. Corrected calcium values after initial saline rehydration were used for analysis and graphical presentation.

\section{Pharmacokinetics}

The pharmacokinetics of pamidronate were studied in seven patients (in study 2) with malignant hypercalcaemia. All patients received $60 \mathrm{mg}$ pamidronate (3-amino-1,1-hydroxypropylidene bisphosphonate as the anhydrous disodium salt) dissolved in $500 \mathrm{ml}$ normal saline as an intravenous infusion over 24 hours (four patients) or 8 hours (three patients).

Blood $(5 \mathrm{ml})$ was collected in lithium heparin tubes at the following times after the start of the infusion: $0.25 \mathrm{~h}, 0.5 \mathrm{~h}, 1 \mathrm{~h}, 2 \mathrm{~h}, 4 \mathrm{~h}, 8 \mathrm{~h}$ and $24 \mathrm{~h}$, the last sample being taken immediately before the end of the infusion. Within a few minutes of collection the blood was centrifuged for the separation of plasma. Plasma samples were stored at $-20^{\circ} \mathrm{C}$ prior to analysis for pamidronate.

The patients were asked to empty their bladder immediately prior to the start of the infusion. Thereafter urine samples were collected as voided for 24 hours, the time and volume being recorded and an aliquot $(20 \mathrm{ml})$ removed and stored at $-20^{\circ} \mathrm{C}$ prior to analysis for pamidronate.

Pamidronate was analysed according to DaleyYates et al. ${ }^{15}$ The method is similar for both plasma and urine samples and involved the following steps. Firstly, an internal standard (1-hydroxy-5-aminopentlylidene-1, 1-bisphosphonate) was added to the sample followed by calcium chloride to cause precipitation of the bisphosphonates as their calcium salts. After centrifugation the precipitate was redissolved in acetic acid. The samples were then separated by high performance ion chromatography, using an on-line two stage post-column reaction. The bisphosphonates were first oxidized to orthophosphate by addition of ammonium persulphate and then reacted with a molybdenumascorbate reagent to yield a phosphomolybdate chromophore detectable at $820 \mathrm{~nm}$.

Animal studies with radiolabelled drug and preliminary studies in patients (Daley Yates, unpublished observations) have demonstrated that the disposition kinetics of pamidronate are multiphasic. However, it is the rapid initial phase of plasma clearance that is responsible for the attainment of plateau concentrations of drug in the plasma of both patients and animals before the end of a 2 hour infusion. Steady-state plasma levels are therefore not determined by the very long terminal elimination phase since most elimination occurs during the infusion before distribution equilibrium is established. The relative insensitivity of the assay coupled with the inability to collect a significant amount of data for post-infusion plasma levels means that it would be inaccurate to measure clearance by extrapolating the area under the concentration/time curve (AUC) to infinity. For this reason total plasma clearance was estimated from a calculated steady-state plasma concentration and the rate of infusion.

The plasma concentration $v s$ time data were analysed using the SIPHAR pharmacokinetic package on an IBM-compatible PC using nonweighted least squares non-linear regression analysis. This method was used to estimate the plateau plasma concentration at the end of the infusion $\left(C_{\mathrm{ss}}\right)$ (assumed steady state). The total plasma clearance $\left(C L_{\mathrm{t}}\right)$ was calculated from $C L_{\mathrm{t}}=R_{\mathrm{inf}} / C_{\mathrm{ss}}$, where $R_{\text {inf }}$ is the rate of infusion. The renal clearance $\left(C L_{\mathrm{r}}\right)$ was calculated from $C L_{\mathrm{r}}=A e_{(0-t)} /$ $A U C_{(0-t)}$, where $A e=$ the amount excreted during the infusion period and $t=$ length of infusion. The 
non-renal clearance $\left(C L_{\mathrm{nr}}\right)$ was estimated from $C L_{\mathrm{nr}}=C L_{\mathrm{t}}-C L_{\mathrm{r}}$.

\section{Results}

\section{Patient characteristics}

Median serum calcium after saline rehydration was slightly lower in the 4 hour infusion arm (3.37 $\mathrm{mmol} / \mathrm{l}$ ) compared to the other three treatment arms ( 2 hour: $3.65 \mathrm{mmol} / 1,8$ hour: $3.7 \mathrm{mmol} / 1$ and 24 hour: $3.7 \mathrm{mmol} / \mathrm{l}$ ) but this difference was not significant. The median ages, tumour types and proportion of patients with skeletal metastases did not differ significantly among the four treatment groups (Table I).

\section{Effects on serum calcium}

Serum calcium fell in all patients and became normal in all but three (one in each of the 2, 4 and 8 hour infusion groups). Figure 1 shows the effect of pamidronate on median-corrected serum calcium concentration in each of the treatment groups. There were no significant differences among the four regimens in either the rate of fall, time to achieve normocalcaemia (median 5 days) or of the nadir value.

\section{Effects on renal function}

There was no renal toxicity. Median serum creatinine values in the $2,4,8$ and 24 hour infusion arms at study entry (before initial rehydration) were 143 (range 78-310), $125(61-395), 150(60-430)$, and $150(70-360) \mu \mathrm{mol} / \mathrm{l}$, respectively. At day 7 these had fallen to $100(50-240), 110(54-389), 80$ $(50-410)$ and $120(70-310) \mu \mathrm{mol} / \mathrm{l}$. No significant differences were seen between treatment groups in terms of initial serum creatinine levels or change in renal function.

\section{Toxicity}

All patients tolerated the infusion regimens of pamidronate well. There were no instances of local

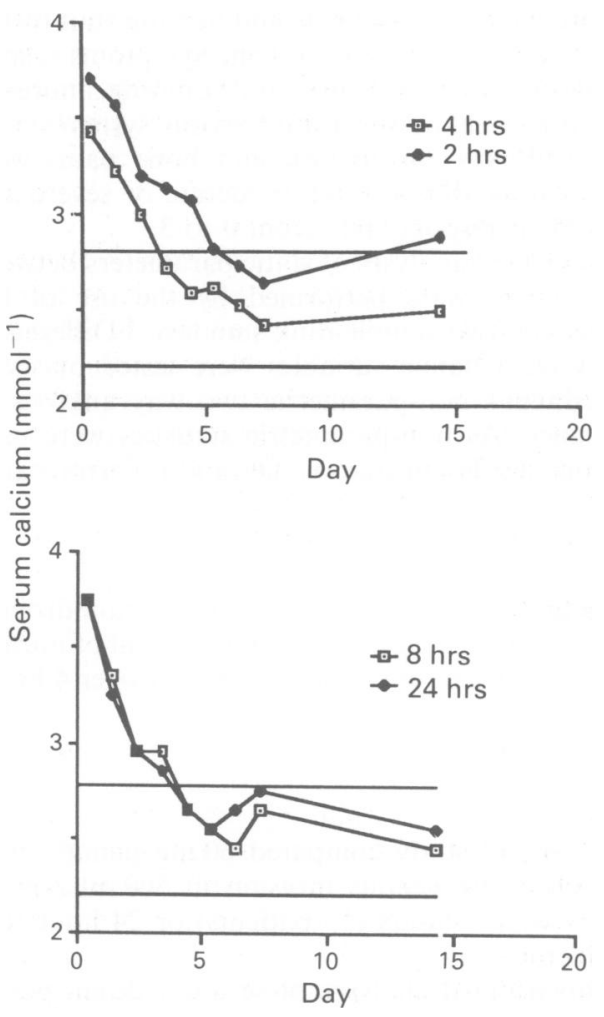

Figure 1 Median corrected serum calcium in patients given $60 \mathrm{mg}$ pamidronate over 2 hours $(n=9), 4$ hours $(n=11), 8$ hours $(n=15)$, or 24 hours $(n=15)$. (Normal range (shown) $2.2-2.65 \mathrm{mmol} / \mathrm{l}$.)

Table I Patient characteristics

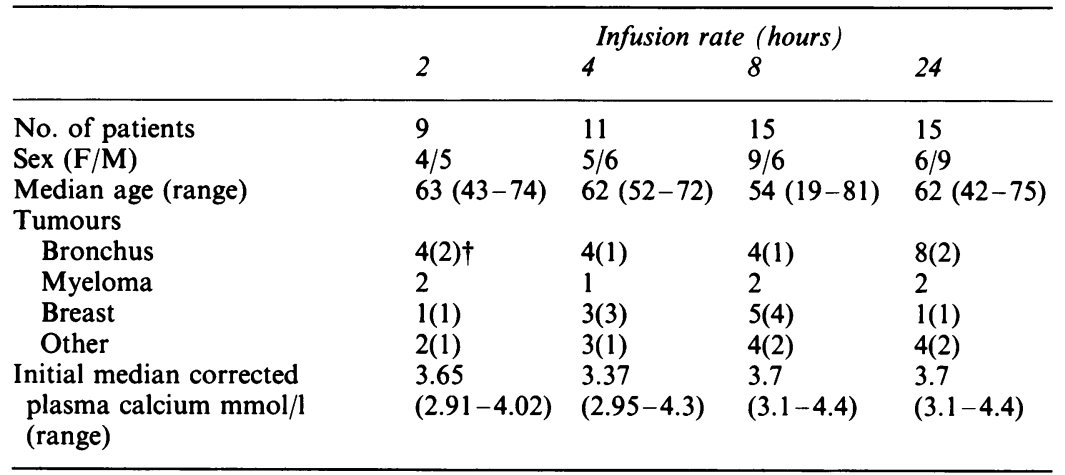

†Figures in parenthesis indicate numbers with bone metastases. 
thrombophlebitis. Transient asymptomatic fever was noted in four subjects. Mild asymptomatic hypocalcaemia (corrected serum calcium $1.95-2.05 \mathrm{~mm} / \mathrm{l}$ ) occurred in four patients.

\section{Recurrence of hypercalcaemia and survival}

There were five early deaths $(<7$ days) after treatment. Two patients died in the 24 hour infusion group, two died in the 8 hour infusion group and one in the 2 hour infusion group.

Twenty-one $(42 \%)$ patients survived for one month after the development of their hypercalcaemia. Patients who survived tended to have tumours responsive to specific antineoplastic measures. Time to recurrence of hypercalcaemia was evaluable in $16 / 47(34 \%)$ of patients. In the other 31 patients 19 died before recurrence of hypercalcaemia and in 12 cases there were alterations in systemic anti-tumour treatment after normocalcaemia had been achieved. Duration of normocalcaemia ranged from 11 to 47 (median 21 days). There were no significant differences in the duration of normocalcaemia between infusion rates (Figure 2).

\section{Effect on symptoms related to hypercalcaemia}

There was a highly significant $(P<0.001)$ improvement in patients' symptoms as assessed by comparison of the sum of median symptom scores at the start of treatment and at one week after treatment (Figure 3). Bone pain, central nervous system symptomatology and pruritus tended not to improve as well as other symptoms. There were no significant differences in the rates of symptom control between infusion regimens.

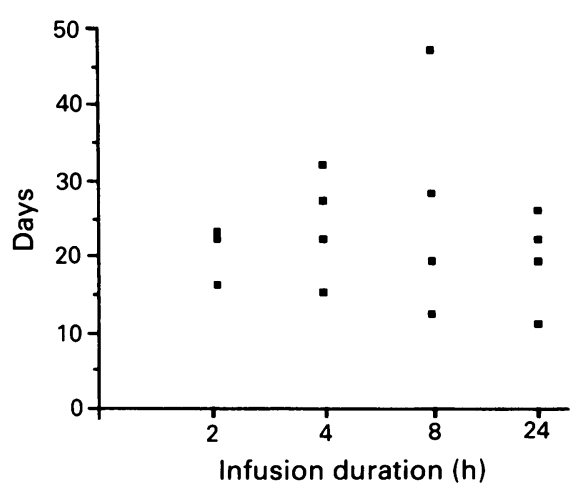

Figure 2 Duration of normocalcaemia after pamidronate.

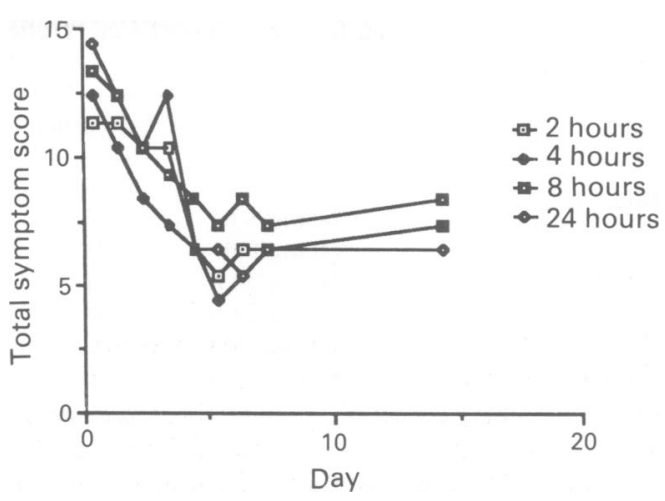

Figure 3 Effect of differing infusion rates of pamidronate on median total symptom score.

\section{Pharmacokinetics}

Table II details the pharmacokinetic parameters for this group of patients. Figure 4 shows the plasma concentration time profile and urine excretion data for patients following infusion of $60 \mathrm{mg}$ pamidronate over $8 \mathrm{~h}$ or $24 \mathrm{~h}$. These patients were typical of those examined and analysis of the plasma concentration data for the period during the infusion, by non-linear least squares regression, revealed an initial half-life of approximately 30 min. The terminal half-life of the drug was very long (many months) and could not be reliably estimated. Despite this long terminal half-life, all patients examined had plasma concentrations of pamidronate approaching a plateau level within the first few hours of the infusion (Figure 4a). In addition most renal elimination occurred during the infusion period (Table II, Figure 4b). After the infusion stopped little additional drug was excreted. The mean total clearance of pamidronate for the seven subjects in this study was $254 \mathrm{ml} / \mathrm{min}$. The mean renal clearance was $38 \mathrm{ml} / \mathrm{min}$. This leaves a non-renal clearance for pamidronate of $216 \mathrm{ml} / \mathrm{min}$. Since this drug is not known to be metabolized this clearance may be predominately uptake into the skeleton, which over the period of this study appears to act as a sink for pamidronate.

\section{Discussion}

All four infusion regimens caused similar falls in corrected serum calcium levels. There were no significant differences between regimens in terms of the nadir calcium levels and time to nadir. All but three patients $(94 \%)$ became normocalcaemic after pamidronate. This is similar to most published studies which confirm that around $90 \%$ of patients become normocalcaemic after treatment with this 
Table II Pharmacokinetic parameters following infusion of $60 \mathrm{mg}$ pamidronate over 8 or 24 hours

\begin{tabular}{lccccc}
\hline Subject & Dose & $C L_{r}(\mathrm{ml} / \mathrm{min})$ & $C L_{t}(\mathrm{ml} / \mathrm{min})$ & $C_{s s}$ & $A e(\mathrm{mg})$ \\
\hline 1 & $60 \mathrm{mg} / 8 \mathrm{~h}$ & 23 & 461 & 0.271 & 6.31 \\
2 & $60 \mathrm{mg} / 8 \mathrm{~h}$ & 25 & 123 & 0.099 & 2.42 \\
3 & $60 \mathrm{mg} / 8 \mathrm{~h}$ & 23 & 311 & 0.402 & 12.16 \\
4 & $60 \mathrm{mg} / 24 \mathrm{~h}$ & 31 & 227 & 0.185 & $3.4^{*}$ \\
5 & $60 \mathrm{mg} / 24 \mathrm{~h}$ & 48 & 150 & 0.277 & 17.06 \\
6 & $60 \mathrm{mg} / 24 \mathrm{~h}$ & 70 & 160 & 0.26 & 23.27 \\
7 & $60 \mathrm{mg} / 24 \mathrm{~h}$ & 46 & 350 & 0.123 & 9.16 \\
Mean \pm s.d. & & $38 \pm 17$ & $254 \pm 124$ & $0.231 \pm 0.104$ & $10.54 \pm 7.57$ \\
\hline
\end{tabular}

$A e=$ amount excreted in urine $0-24 \mathrm{~h} ; C L_{\mathrm{r}}=$ renal clearance $=A e_{(0-t)} /$ plasma $A U C_{(0-t)}$; $t=$ length of infusion; $C L_{\mathrm{t}}=$ total clearance $=$ rate of infusion $/ C_{\mathrm{ss}} ; C_{\mathrm{ss}}=$ plasma concentration at end of infusion estimated, from non-linear least squares regression analysis, using a single exponent fit; ${ }^{*}(0-14 \mathrm{~h})$.
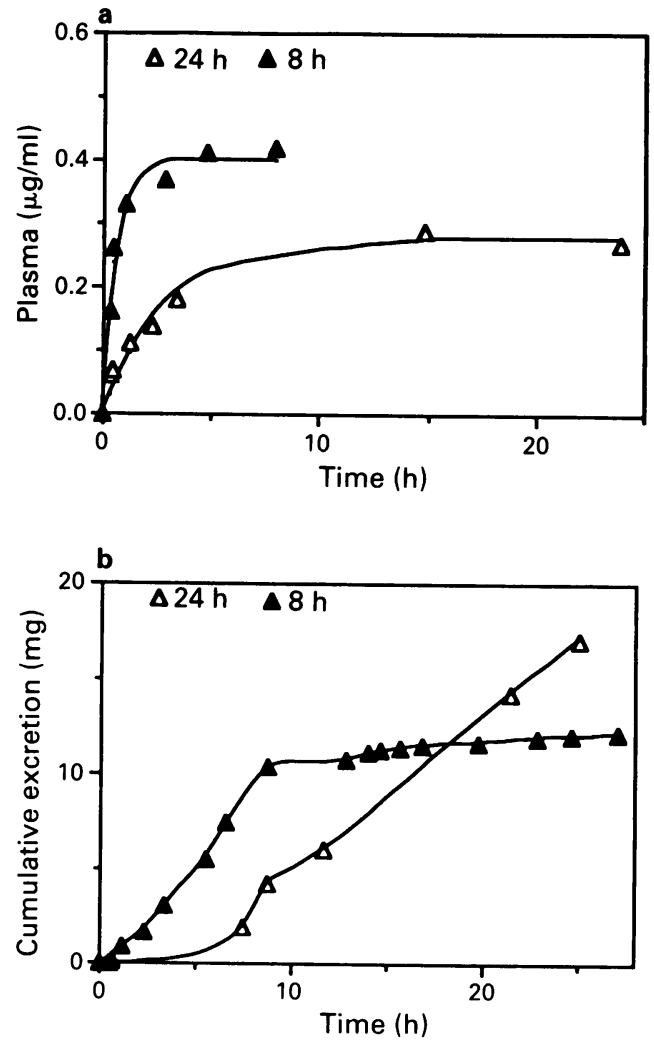

Figure 4 Representative plasma and urinary data for two subjects (Table II, patients 3 and 5) receiving $60 \mathrm{mg}$ pamidronate as an infusion over $8 \mathrm{~h}$ or $24 \mathrm{~h}$. (a) shows the approach to plateau plasma concentration during the infusion, the solid line is a single exponential model fitted to the data. (b) depicts the cumulative urinary excretion of pamidronate for these subjects; most elimination occurs during the infusion period. agent. Time to relapse of hypercalcaemia (median 21 days) also appeared to be independent of infusion rate. In the study of Ralston et al. ${ }^{8}$ using a single of infusion of $30 \mathrm{mg}$ pamidronate given over 4 hours median time to relapse was 29 (range 18-90) days although only six patients were evaluable for relapse in this study. A similab median 'time to recurrence' of 21 days was foung by Morton et al. ${ }^{10}$ who compared a single infusion of $60 \mathrm{mg}$ pamidronate to fractionated daily infu? sions for 2 or 4 days to the same total dose. Symptomatic response also appeared to be independent of infusion rate, although it will be noted that the median symptom score did not return to zero after treatment indicating perhaps that these symptoms were not solely due to hypercalcaemia.

This study also confirms the very poor prognosis of these patients with a median actual survival time of less than one month for patients with no effective anti-tumour therapy. However, the unpleasant symptoms of hypercalcaemia still warrant early correction of this metabolic abnormality wherever possible.

Clearly short infusions of pamidronate are more convenient than fractionated or prolonged infusions and our study has demonstrated the efficacy and safety of two hour infusions of $60 \mathrm{mg}$ pamidronate in the treatment of hypercalcaemia of malignancy. There is also increasing interest in the use of bisphosphonates for the control of lytic bone disease, ${ }^{4,5}$ for Paget's disease ${ }^{16}$ and osteoporosis. ${ }^{17}$ The demonstration of the safety and efficacy of high infusion rates in hypercalcaemia may simplify outpatient therapy for these conditions.

These preliminary data on the pharmacokinetics of intravenous pamidronate show the drug to have a high clearance, due predominantly to probable calcified tissue retention and partly to renal 
clearance. Most of the drug is cleared from the plasma before distribution equilibrium is achieved and this results in the rapid attainment of apparent near steady-state plateau levels in the plasma within a few hours from the start of an infusion. However, the initial short half-life of the drug soon gives way to a prolonged elimination phase which

\section{References}

1. Ryzen, E., Martodam, R.R., Troxell, M. et al. Intravenous etidronate in the management of malignant hypercalcaemia. Arch Intern Med 1985, 145: 449-452.

2. Jacobs, T.P., Siris, E.S., Bilezekian, J.P., Baguiran, D.C., Shane, E. \& Canfield, R.E. Hypercalcaemia of malignancy: treatment with intravenous dichloromethylene diphosphonate. Arch Intern Med 1981, 94: 3212-3217.

3. Sleeboom, H.P., Bijvoet, O.L.M., van Oosteroom, A.T., Gleed, J.T. \& O'Riordan, J.L.H. Comparison of intravenous (3-amino-1-hydroxypropylidene) 1,1 bisphosphonate and volume repletion in cancer associated hypercalcaemia. Lancet 1983, i: 239-240.

4. Morton, A.R., Cantrill, J.A., Pillai, G.V., McMahon, A., Anderson, D.C. \& Howell, A. Sclerosis of lytic metastases after aminohydroxypropylidene bisphosphonate (APD) in patients with breast carcinoma. $\mathrm{Br}$ Med J 1988, 297: $772-773$.

5. Coleman, R.E., Woll, P.J., Miles, M. \& Rubens, R. 3-amino 1, 1 hydroxypropyledine bisphosphonate (APD) for the treatment of bone metastases from breast cancer. $\mathrm{Br} \mathrm{J}$ Cancer 1988, 58: $621-625$.

6. Fogelman, I., Smith, L., Mazess, R., Wilson, M.A. \& Bevan, J.A. Absorption of oral diphosphonate in normal subjects. Clin Endocr 1986, 24: 57-62.

7. Dodwell, D.J., Howell, A., Morton, A. et al. Biochemical effects, antitumour activity and pharmacokinetics of oral and intravenous pamidronate (APD) in the treatment of skeletal breast cancer. Proc 31st Meeting BACA/ACP 1990, Abstract No. 8.11.

8. Ralston, S.H., Patel, U., Fraser, W.D. et al. Comparison of three intravenous bisphosphonates in cancer-associated hypercalcaemia. Lancet 1989 , ii: $1180-1182$.

9. Thiebaud, D., Jaeger, P., Jacquet, A.F. \& Burkhardt, P. Dose response in the treatment of hypercalcaemia of malignancy by a single infusion of the bisphosphonate AHPrBP. J Clin Oncol 1988, 6: 762-765. probably reflects the slow release of the drug from deep tissue compartments such as bone. In this respect these findings are consistent with data from animal studies where bone, soft tissue, plasma and urine data are available (Hoggarth et al., unpublished data).

10. Morton, A.R., Cantrill, J.A., Craig, A.E. et al. Comparison of single versus daily aminohydrosypropylidene bisphosphonate (APD) for the treatment of the hypercalcaemia of malignancy. $\mathrm{Br}$ Med J 1988, 296: 166-169.

11. Cantwell, B.M.J. \& Harris, A.L. Effect of single high dose infusion of aminohydroxypropylidene diphosphonate on hypercalcaemia caused by cancer. $B r$ Med $J$ 1987, 294: 467-562.

12. Thiebaud, D., Jaeger, P., Jacquet, A.F. \& Burkhardt, P. A single day treatment of tumour-induced hypercalcaemia by intravenous aminohydroxypropylidene bisphosphonate. $J$ Bone Min Res 1986, 1: 555-562.

13. Bounameaux, H., Schifferli, Montani, J.P., Jung, A. \& Chatelant, F. Renal failure associated with intravenous diphosphonates. Lancet 1983, i: 471.

14. Bourke, G.J., Daly, L.E. \& McGilvray, J. Interpretation and Uses of Medical Statistics. Blackwell Scientific Publications, Oxford, 1985.

15. Daley-Yates, P.T., Gifford, L.A. \& Hoggarth, C.R. Assay of 1-hydroxy-3-aminopropylidene-1,1-bisphosphonate, and related bisphosphonates, in human urine and plasma by high performance ion chromatography. J Chromatography 1989, 490: $329-338$.

16. Harinck, H.I.J., Bijvoet, O.L.M., Blanksma, H.J. et al. Efficaceous management with APD in Paget's disease of bone. Clin Orthop Rel Res 1987, 217: 79-98.

17. Reid, I.R., Heap, S.W., King, A.R. \& Ibbotson, H.K. Two-year follow up of bisphosphonate (APD) treatment in steroid osteoporosis. Lancet 1988, ii: 1144.

18. Hoggarth, C.R., Bennett, R. \& Daley-Yates, P.T. The pharmacokinetics and distribution of pamidronate for a range of doses in the mouse. Calcif Tissue Int 1991, (in press). 